\title{
'||||||||||||||||||||||||||||||||||||||||||||||||||||||||||||||||||.
}

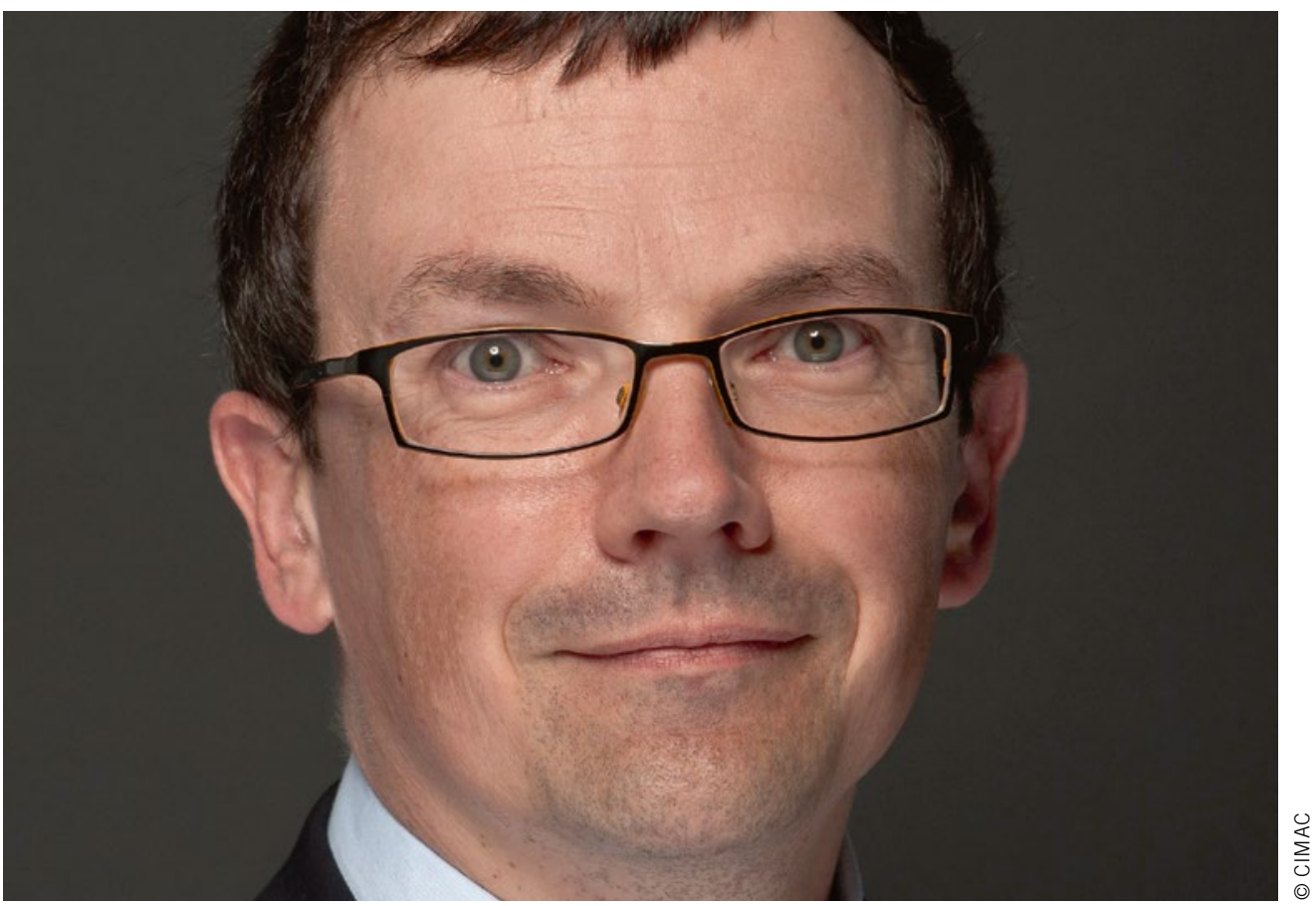

Peter Müller-Baum Secretary General CIMAC Managing Director, VDMA Engines and Systems

\section{System Integration The Future of Efficient Power}

Over recent years, the term 'System Integration' has gained currency in industry. Looking at large engines, the few percentage points of efficiency we stand to gain by optimising and fine-tuning state-of-the-art products that already set the standard for fuel efficiency is only a trickle compared to the tide of improvements achievable by optimising entire drive systems. Optimisation at this all-encompassing level is what we call 'System Integration' and aims to ensure that individual elements in a drive system interact in the most effective way.

Take an offshore vessel. Its energy efficiency is of paramount interest to its owners, and as they look to alternative methods of propulsion, like dual-fuel engines and electric or hybrid drives, overall complexity increases. Add the advanced exhaust aftertreatment systems required for compliance with current and future emissions regulations and complexity multiplies further.

As a result, the efficient integration of all necessary sub-systems will be the focal point of future performance improvements. To achieve this system integration dictates the coming together at one table of all the relevant stakeholders - engine developers, component suppliers, research organisations, system integrators, Classification Societies and engine users - to discuss optimum ways of connecting, interfacing and operating an entire system. Currently, our industry lacks know-how in this area and is only beginning to find its feet in what we can call the best practices of an integrator.

The good news is that the deficits have been identified and are being resolutely targeted, with CIMAC taking a leading role. An event with the technical and global reach of the CIMAC Congress will, in my view, be an important platform for further discussion across the depth and breadth of this topic and an excellent stage for experts from makers and users to exchange their ideas for collaborating along similar lines.

It is a matter of pride at CIMAC that we are one of the early birds in recognising the importance of system integration and optimisation. This is evidenced by the formation of Working Group 20 - System Integration more than a year ago. We have received a tremendous response from CIMAC members and the Congress in Helsinki is an ideal opportunity to showcase "WG 20", as we aim to springboard participation by a broader industrial base, including battery manufacturers, auxiliary system suppliers etc. The Working Group has already prepared fertile ground for what I feel is a radical scope for development in our industry.

System Integration is imminent, the foreseeable gains are just too big to be ignored, and it's only a matter of time before we harvest the first fruits. 